\title{
Comparison between Bruce and Ramp Protocols for Exercise Testing in the Diagnosis of Myocardial Ischemia
}

Thiago Teixeira da Silveira Fagundes, ${ }^{\circledR}$ Carolina Christianini Mizzaci, ${ }^{\circledR}$ Susimeire Buglia, ${ }^{\circledR}$ Fabricio da Costa Wohnrath, Flavia Medina, João França, ${ }^{\odot}$ Rica Dodo Delmar Buchler, ${ }^{\circledR}$ Luiz Eduardo Mastrocola, ${ }^{\circledR}$ Romeu Sérgio Meneghelo ${ }^{\circledR}$ Instituto Dante Pazzanese de Cardiologia, São Paulo, SP-Brazil

\section{Abstract}

Background: Exercise tests are an important tool in the investigation of myocardial ischemia. The ramp protocol has gained increasing importance in clinical practice because of the possibility of individualizing its exercise intensity.

Objective: To assess and compare the sensitivity, specificity, and accuracy of Bruce and ramp protocols for exercise testing in the diagnosis of myocardial ischemia considering myocardial perfusion scintigraphy as the reference standard. Secondary objectives included the assessment of hemodynamic profiles, functional capacity, and the incidence of arrhythmias in each of the protocols.

Methods: Participants underwent exercise testing using the ramp and Bruce protocols, and the tests' diagnostic power was assessed. For testing the difference between data provided by both protocols, we used a paired Student's t-test or Wilcoxon test, depending on the assumption of data normality. The level of significance adopted for all tests was $5 \%$.

Results: The ramp protocol showed sensitivity, specificity, and accuracy values of $55.6 \%, 82.4 \%$, and $76.7 \%$, respectively, whereas the Bruce protocol had results of $77.8 \%, 64.7 \%$, and $67.4 \%$, respectively. The maximum heart rate and double product at peak exercise were significantly higher in the Bruce protocol $(p=0.043$ and $p=0.040$, respectively). No differences were observed between the incidence of arrhythmias in both protocols.

Conclusion: The Bruce protocol presented higher sensitivity for detecting ischemia on the exercise test, while the ramp protocol presented higher specificity and accuracy.

Keywords: Myocardial Ischemia/diagnosis; Exercise; Jogging; Exercise Test; Myocardial Perfusion Imaging; Coronary Artery Disease; Sensitivity and Specificity.

\section{Introduction}

The stress test consists in a procedure where an individual undergoes programmed physical exercise in order for the physician to assess clinical, hemodynamic, and electrocardiographic responses. ${ }^{1}$ The exercise can be performed using a treadmill or a stationary cycle ergometer, and many protocols are available according to the test objective, being adaptable to patient conditions.

Even though it was created more than 5 decades ago, the Bruce protocol is still the most widely used in the world's main laboratories. ${ }^{2}$ Its increments are performed every 3 minutes, but an increase of around 3 metabolic equivalents of task (MET) at each stage may hinder the adaptation of sedentary individuals and those who have heart diseases and physical limitations, leading to the early interruption of the test.

Technological advances allowed the creation of new protocols with smoother speed and incline increments, the so-called ramp tests. ${ }^{3}$ The first report of the ramp protocol is from the 1980s using a stationary cycle ergometer and, in the following decade, with a treadmill. ${ }^{4,5}$

The main advantage of the ramp protocol, with smoother and more linear increments when

Mailing Address: Thiago Fagundes

Av. Dr. Dante Pazzanese, 500. Postal Code: 04012-909, São Paulo, SP - Brazil.

E-mail: thiagotsfagundes@hotmail.com 
compared to protocols that use abrupt work increments, would be a better physiological response when considering hemodynamic and ventilatory variables. ${ }^{3,5,6}$ Moreover, speed and incline can be individually adapted to each patient. ${ }^{3-5}$

However, literature is lacking when it comes to robust evidence of the accuracy of this protocol for myocardial ischemia, since most diagnostic studies of stress tests were performed using stage protocols. ${ }^{7}$

\section{Objectives}

Our primary objective was to assess and compare the sensitivity, specificity, and accuracy of the Bruce protocol, owing to its wide application on clinical practice, with the treadmill ramp protocol. The reference standard used in this study was exercise myocardial perfusion scintigraphy.

As for secondary objectives, we aimed to assess and compare the hemodynamic behavior, presence of arrhythmias, and functional capacity between both protocols.

\section{Methods}

This study was performed at a cardiology referral center in the city of São Paulo. Our sample included male and female participants aged 18 or older, who underwent treadmill exercise myocardial perfusion scintigraphy as recommended by their respective physicians. Patient selection was performed consecutively between October 2018 and February 2020.

Patents who had a resting electrocardiogram with an ST segment depression $>1 \mathrm{~mm}$, left bundle branch block, atrial fibrillation, pacemaker rhythm, or ventricular preexcitation were not included. Exclusion criteria were (i) therapeutic interventions (angioplasty or myocardial revascularization) between any of the study phases; (ii) patient dropouts at any phase; and (iii) contraindications to the exercise test, according to the literature. ${ }^{8}$

After myocardial scintigraphy examination and the invitation to participate in the study, individuals were randomized for exercise testing using the Bruce and ramp protocols. The randomization was performed through codes generated by the Sealed Envelope software. ${ }^{9}$ The interval between each phase of the study was 14 days. Study phases are illustrated on Figure 1.

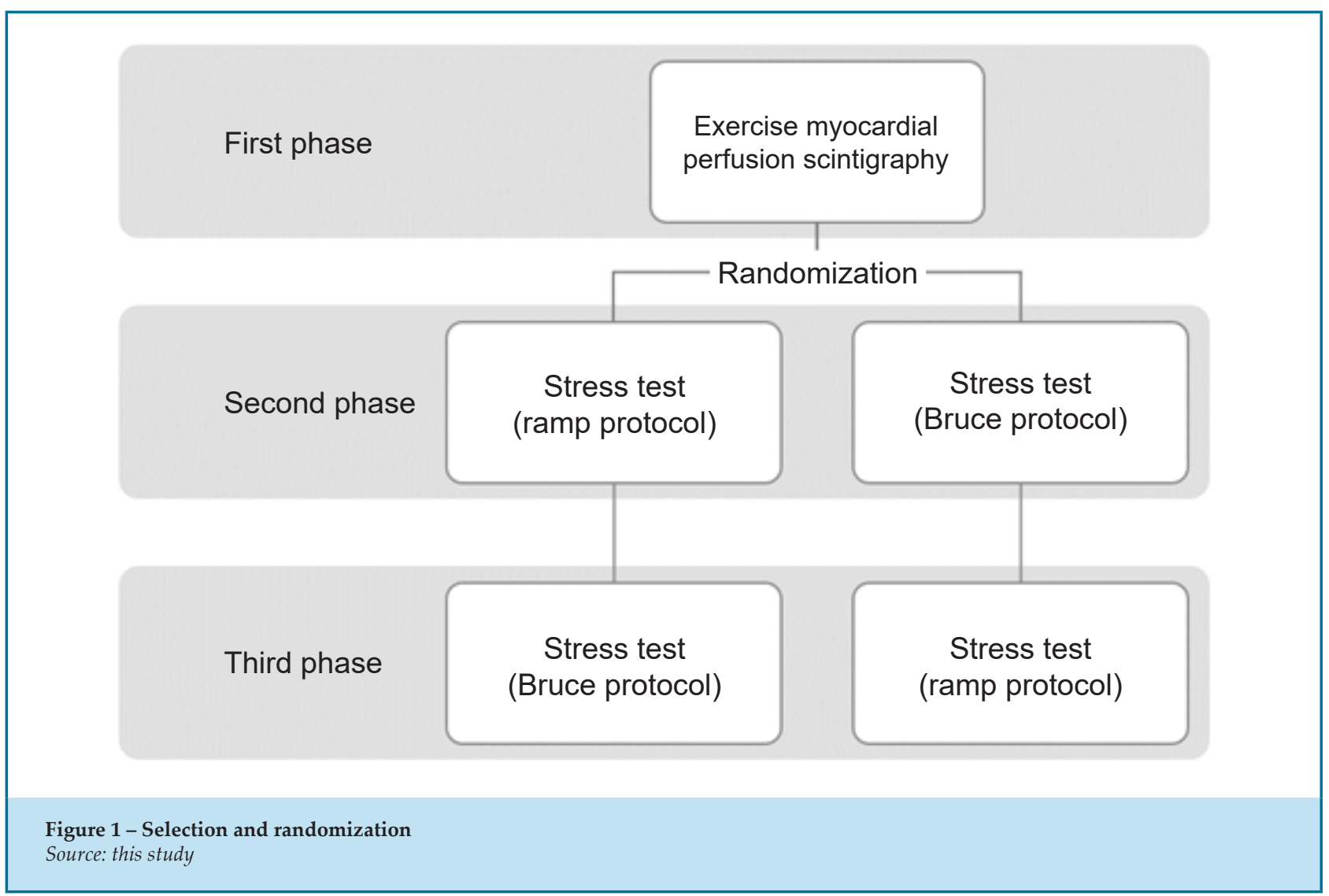


All participants received a free and informed consent form (FICF) that was previously approved by the Research Ethics Committee (CEP) and were also informed of the risks and benefits of performing the study. Participants were instructed to wear appropriate clothes and shoes during the test. Moreover, they were instructed not to drink or smoke and to have a light meal up to 3 hours before the test.

According to the last myocardial scintigraphy guideline and to the nuclear medicine unit of the center where this study was conducted, participants were instructed to interrupt the use of medications with negative chronotropic effects (betablockers and dihydropyridine calcium channel blockers) 72 hours before each test. ${ }^{10}$ This instruction was adopted in all study phases to avoid differences in the sensitivity of ischemia detection between myocardial scintigraphy and the subsequent exercise tests. ${ }^{8,11,12}$ Other medications were maintained in all study phases.

For the ramp protocol, functional capacity was estimated through an interview with the participant using the Portuguese version of the Veterans Specific Activity Questionnaire (VSAQ). ${ }^{1,13}$ Increments were automatically calculated by the software based on the functional activity programming and a target duration of 10 minutes.

During the test, both in the Bruce and ramp protocols, we allowed patients to use front or side bars for maintaining balance, with minimal support. Participants were stimulated to reach exhaustion, as long as there were no criteria recommending the interruption of the test. Functional capacity was calculated using the equation derived from the Fitness Registry and the Importance of Exercise (FRIEND) registry. ${ }^{14}$

The interpretation of exercise tests was performed by an experienced physician who was blinded to the participant data, test protocol, and myocardial scintigraphy results. Physicians overseeing the tests were also unaware of the results of the previously performed scintigraphy.

ST segment measurement was performed in 3 consecutive complexes, considering the last PR segment as baseline. Tests were considered positive for myocardial ischemia when they presented, at peak exercise or recovery phases, one of the following alterations:

a) A horizontal or downsloping ST segment depression $\geq 1.0 \mathrm{~mm}$ measured at the J point.

b) An upsloping ST segment depression $\geq 1.5 \mathrm{~mm}$ measured $80 \mathrm{~ms}$ after the J point. c) An ST segment elevation $\geq 1.0 \mathrm{~mm}$ in the absence of a pathological Q wave.

In patients with right bundle branch block, we did not analyze the V1, V2, and V3 leads since they presented alterations in ventricular repolarization when at rest, which could be intensified during exercise and hinder the electrocardiographic analysis of ischemia. ${ }^{15}$

Arrhythmias were recorded during and after exercise and classified as complex ventricular arrhythmias: frequent ventricular extrasystoles (over 10\% of QRS complexes in a 30-second period); bigeminy; or ventricular tachycardia.

Myocardial scintigraphy results were independently analyzed by blinded physicians at the nuclear medicine unit. Images at rest and after exercise were evaluated, aiming to compare alterations in myocardial perfusion between phases. Scintigraphy results were considered positive for myocardial ischemia when a transient low uptake was observed, that is, a difference in perfusion between resting and stress states. In this study, analyses were conducted categorically, that is, results were considered positive or negative for ischemia and were classified according to the extent of left ventricular myocardial impairment ${ }^{16}$, according to the following description:

a) mild - stress-induced perfusion defect encumbering less than $5 \%$ of the myocardium;

b) moderate - stress-induced perfusion defect encumbering $5 \%$ to $9.9 \%$ of the myocardium;

c) important - stress-induced perfusion defect encumbering $10 \%$ or more of the myocardium.

\section{Statistical analysis}

Participant data and test results were registered using Microsoft Excel 365 software. The analysis of collected data was performed using R 4.0.2 software. The DTComPair package was also used for calculating confidence intervals (CIs).

For testing the difference between data derived from each of the studied protocols, we used the paired Student's t-test or the Wilcoxon test when our data normality assumption was not satisfied via a Kolmogorov-Smirnov test. Continuous variables with normal distribution were presented through means and standard deviations, and those that did not have a normal distribution were presented as medians and interquartile ranges. For comparing the incidence of 
arrhythmias between protocols, we used the McNemar test, since participants underwent the same test using different protocols. The significance level adopted for all tests was $5 \%$.

Sensitivity, specificity, and accuracy calculations, in addition to likelihood ratios and predictive values, were calculated for all protocols so that each classification could be compared to that of the reference standard (myocardial perfusion scintigraphy). CIs were constructed considering a 95\% confidence level.

For comparing ST segment analyses for each protocol and estimating the odds ratio, we adjusted a statistical model considering the predominant morphology as the response variable and the protocol (ramp or Bruce) as the explanatory variable. We adjusted an ordinal logistic regression model with proportional odds considering a mixed model, since assessments by both protocols were performed with the same participants.

\section{Results}

After patient selection, our sample contemplated 43 participants who went through all 3 study phases: myocardial scintigraphy and exercise testing with the Bruce and ramp protocols, according to randomization. Our first results refer to sample characterization and are described on Table 1.

Out of 86 tests, the criteria for interrupting the study were exhaustion $(94.1 \%)$, impairing thoracic pain $(3.5 \%)$, nonsustained ventricular tachycardia $(1.2 \%)$, and a drop in systolic arterial pressure (SAP) along with cardiovascular symptoms $(1.2 \%)$. Data referring to the

Table 1 - Clinical characteristics of the selected sample

\begin{tabular}{|c|c|}
\hline Sex - male & $32(74.4 \%)$ \\
\hline Weight (kg) & $79.65( \pm 12.51)$ \\
\hline Height (cm) & $166( \pm 76.46)$ \\
\hline Age & $61.72( \pm 8.64)$ \\
\hline \multicolumn{2}{|l|}{ Medical history } \\
\hline Systemic arterial hypertension & $37(86.0 \%)$ \\
\hline Diabetes mellitus & $20(46.5 \%)$ \\
\hline Dyslipidemia & $37(86.0 \%)$ \\
\hline Smoking & $18(41.9 \%)$ \\
\hline Coronary artery disease & $28(65.1 \%)$ \\
\hline Previous acute myocardial infarction & $13(30.2 \%)$ \\
\hline Previous angioplasty & $9(20.9 \%)$ \\
\hline Myocardial revascularization & $12(27.9 \%)$ \\
\hline \multicolumn{2}{|l|}{ Continuous medications } \\
\hline Platelet antiaggregants & $37(86.0 \%)$ \\
\hline Statin & $38(88.4 \%)$ \\
\hline ACEI/ARB & $34(79.1 \%)$ \\
\hline Diuretics & $19(44.2 \%)$ \\
\hline Nitrate & $7(16.3 \%)$ \\
\hline Beta blockers & $33(76.7 \%)$ \\
\hline
\end{tabular}


tests and comparing the ramp and Bruce protocols are described on Table 2 .

Participants presented at least one episode of arrhythmia in $60.5 \%$ of the ramp protocol tests, of which only $7 \%$ were complex ventricular arrhythmias. On the other hand, the incidence of arrhythmias was $69.8 \%$ in Bruce protocol tests, with $9.3 \%$ of complex ventricular arrhythmias. No statistically significant difference was observed between both protocols considering episodes of arrhythmia $(p=0.453)$ and complex ventricular arrhythmia $(p=1.000)$. We also analyzed the incidence of arrhythmias between test phases (exercise and recovery) and did not find significant differences $(p=0.211$ and $p=0.453$, respectively).

Out of the performed tests, the ramp protocol presented criteria for myocardial ischemia in 11 participants (25.5\%) while the Bruce protocol was positive in 19 cases $(44.2 \%)$, considering the study criteria. The Bruce protocol resulted in 12 participants with false positive results and 2 participants with false negative results, whereas the ramp protocol had more false negative results (4 participants) and only 6 false positive results. These data can be seen on Figure 2.

The difference between protocols as to the morphological classification of the ST segment depression was significant ( $\mathrm{p}=0.008$ ), and participants who underwent the Bruce protocol had a higher chance of developing morphologies related to a worse prognosis when compared to the ramp protocol (odds ratio 5.83, 95\% CI 1.58-21.45), as demonstrated on Figure 3.
Nine participants had a transient low uptake at myocardial scintigraphy, indicating that $21 \%$ of the study sample presented myocardial ischemia diagnosed by the standard reference test. Five participants presented discrete alterations at myocardial scintigraphy, 2 had moderate alterations, and 2 had important impairment.

The sensitivity, specificity, and accuracy of each of the protocols and their respective CIs, as well as the likelihood ratio and predictive values for each protocol, are presented on Table 3.

\section{Discussion}

In this study, both protocols had their mean duration within the recommended 8-12-minute interval, which allows the optimization of $\mathrm{VO} 2$ max in this period of time. ${ }^{1,17-19}$ When undergoing the ramp protocol, participants had a longer exercise duration, which was justified by the adaptation of patients to smoother work increments, corroborating other studies. 5,20,21

Estimating functional capacity through objective tools such as the VSAQ can help in elaborating the ramp protocol. The questionnaire, initially developed for male individuals, was further validated in other populations including women and other nationalities; it was thus revealed to be a useful instrument for programming ramp protocol data, since this protocol can be influenced by the physician's experience. . $^{13,22-24}$

Table 2 - Clinical data of exercise tests

\begin{tabular}{|c|c|c|c|}
\hline & Ramp & Bruce & p-value \\
\hline Duration of exercise (seconds) & $706( \pm 166)$ & $600( \pm 165)$ & $<0.001$ \\
\hline Resting HR (bpm) & $75.86( \pm 14.66)$ & $72.51( \pm 12.80)$ & 0.066 \\
\hline Maximum HR (bpm) & $146( \pm 21.37)$ & $150( \pm 18.10)$ & 0.043 \\
\hline$\%$ maximum HR & $92.22 \%( \pm 11.96)$ & $94.85 \%( \pm 9.43)$ & 0.042 \\
\hline $\mathrm{HR}$ at the first minute of recovery (bpm) & $121.84( \pm 21.22)$ & $123.47( \pm 18.81)$ & 0.708 \\
\hline Resting SAP $(\mathrm{mmHg})^{*}$ & $130.0[120.0 ; 140.0]$ & $130.0[120.0 ; 140.0]$ & 0.441 \\
\hline Maximum SAP $(\mathrm{mmHg})^{*}$ & $190.0[170.0 ; 207.5]$ & $190.0[180.0 ; 220.0]$ & 0.075 \\
\hline Maximum DP (bpm.mmHg $\left.\times 10^{3}\right)^{*}$ & $27.7[24.0 ; 32.3]$ & $29.88[26.15 ; 32.63]$ & 0.040 \\
\hline Workload (MET) & $9.46( \pm 2.18)$ & $9.57( \pm 2.27)$ & 0.109 \\
\hline \multicolumn{4}{|c|}{$\begin{array}{l}\text { Source: this study } \\
\text { * values represented by median and interquartile range } \\
\text { HR: heart rate; bpm: beats per minute, SAP: systolic arterial pressure; mmHg: millimeters of mercury; DP: double product; MET: metabolic equivalent of ta }\end{array}$} \\
\hline
\end{tabular}




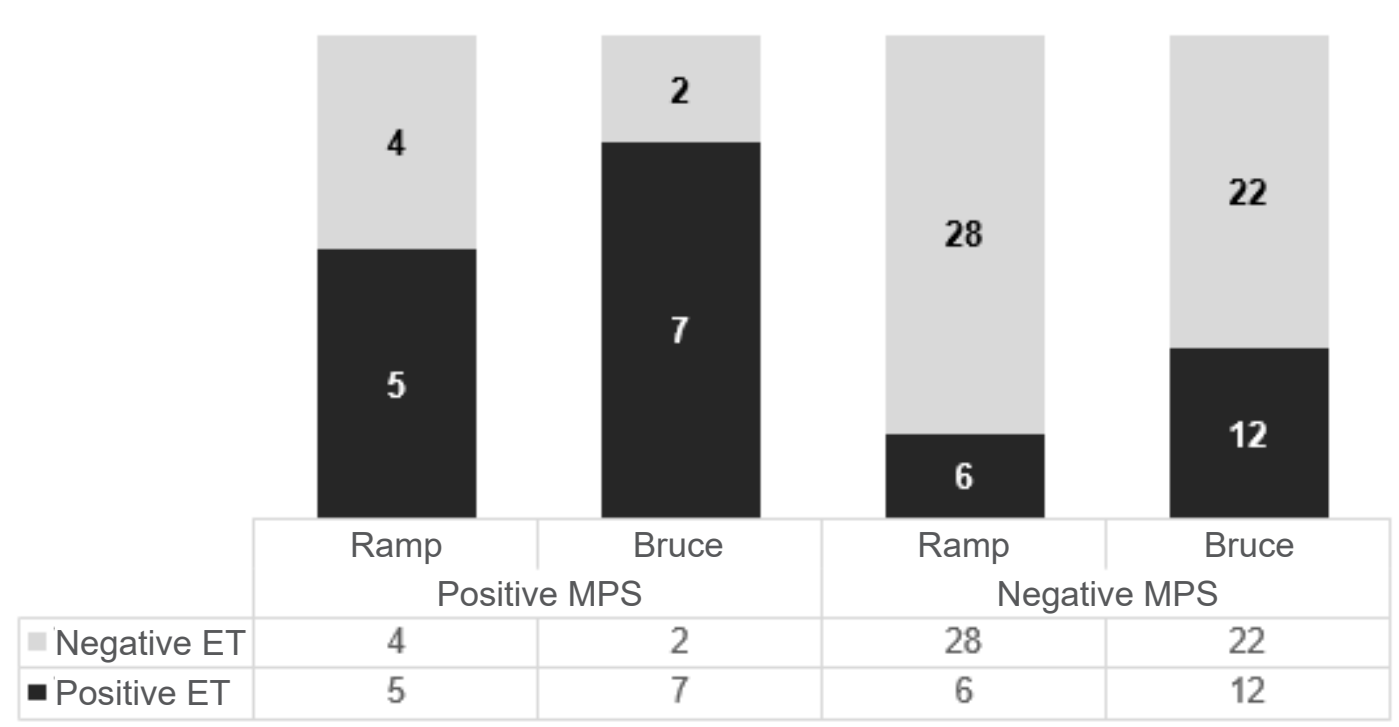

Figure 2 - Test results divided by protocol and compared to myocardial scintigraphy results

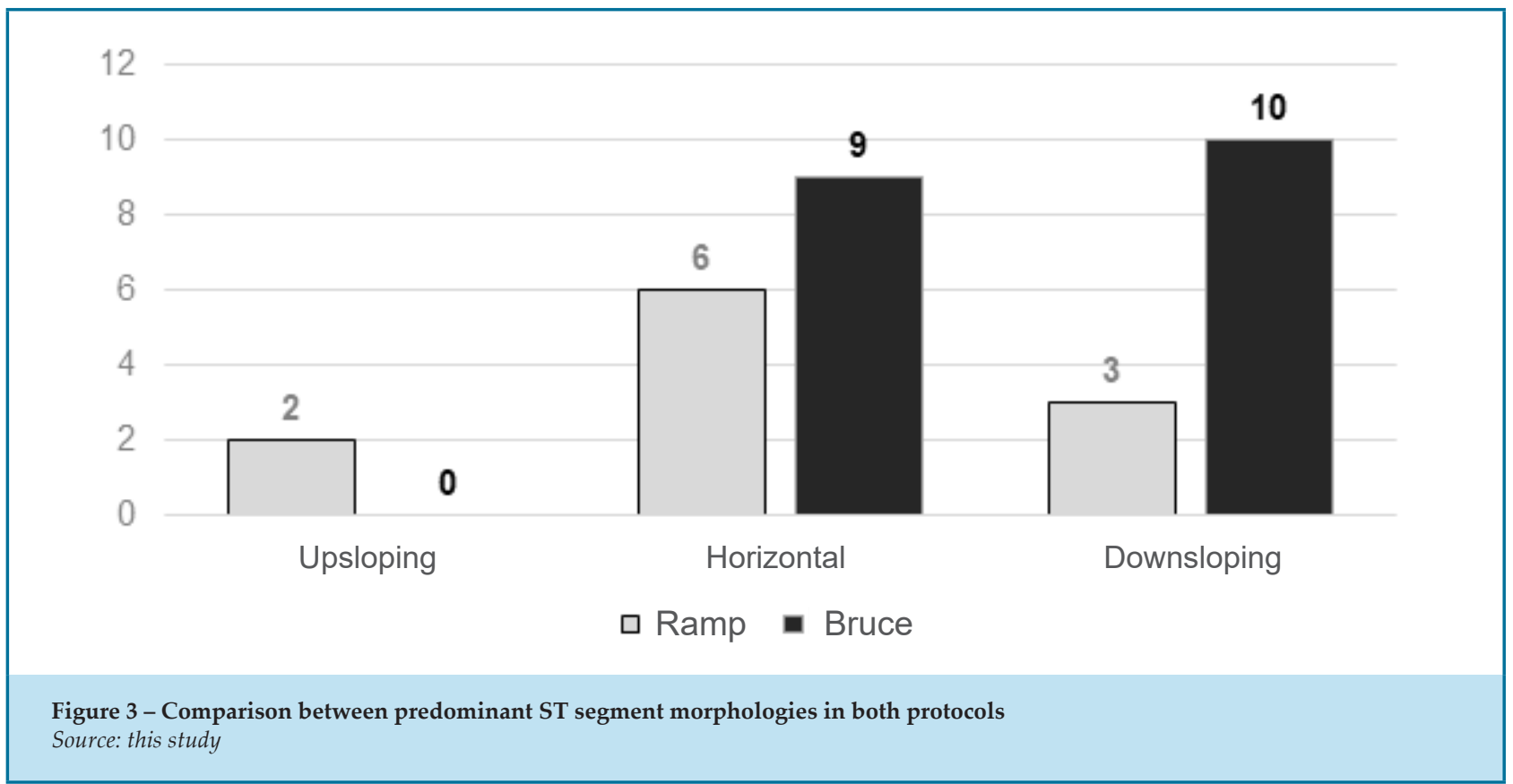

Functional capacity was calculated using the equation derived from the FRIEND registry, which has been applied to different protocols (including the Bruce and ramp protocols) in healthy populations and in those with coronary artery disease (CAD). ${ }^{14,25,26}$ Its results are closer to the $\mathrm{VO} 2$ max measured through ergospirometry than to those obtained by the American
College of Sports Medicine (ACSM) equation, which is still widely used. ${ }^{14,25,26}$

Stress-induced arrhythmias are associated with a higher incidence of cardiovascular events and higher long-term mortality. ${ }^{27-31}$ Jouven et al. ${ }^{27}$ demonstrated that asymptomatic individuals who presented complex ventricular arrhythmias during the exercise period had 
Table 3 - Diagnostic power of protocols evaluated in this study

\begin{tabular}{|c|c|c|c|c|c|c|}
\hline & \multicolumn{3}{|c|}{ Ramp } & \multicolumn{3}{|c|}{ Bruce } \\
\hline & \multirow[b]{2}{*}{ Value } & \multicolumn{2}{|c|}{$95 \%$ CI } & \multirow[b]{2}{*}{ Value } & \multicolumn{2}{|c|}{$95 \%$ CI } \\
\hline & & $\begin{array}{c}\text { Inferior } \\
\text { limit }\end{array}$ & $\begin{array}{c}\text { Superior } \\
\text { limit }\end{array}$ & & $\begin{array}{c}\text { Inferior } \\
\text { limit }\end{array}$ & $\begin{array}{c}\text { Superior } \\
\text { limit }\end{array}$ \\
\hline Sensitivity & $55.6 \%$ & $23.1 \%$ & $88.0 \%$ & $77.8 \%$ & $50.6 \%$ & $100.0 \%$ \\
\hline Specificity & $82.4 \%$ & $69.5 \%$ & $95.2 \%$ & $64.7 \%$ & $48.6 \%$ & $80.8 \%$ \\
\hline Accuracy & $76.7 \%$ & $64.1 \%$ & $89.4 \%$ & $67.4 \%$ & $53.4 \%$ & $81.4 \%$ \\
\hline PLR & 3.1 & 1.2 & 8.0 & 2.2 & 1.2 & 3.9 \\
\hline NLR & 0.5 & 0.3 & 1.1 & 0.3 & 0.1 & 1.2 \\
\hline PPV & $45.5 \%$ & $16.0 \%$ & $74.9 \%$ & $36.8 \%$ & $15.2 \%$ & $58.5 \%$ \\
\hline NPV & $87.5 \%$ & $76.0 \%$ & $99.0 \%$ & $91.7 \%$ & $80.6 \%$ & $100.0 \%$ \\
\hline
\end{tabular}

a higher risk of cardiovascular death. Dewey et al., ${ }^{30}$ however, observed that the presence of ventricular arrhythmias at the recovery phase was associated with a worse prognosis when compared to the exercise phase, which is similar to what was found in a recent metaanalysis. $^{31}$

The incidence of stress-induced arrhythmias was superior in our study when compared to the literature, which can be justified by the severity of the studied population, referred by a high-complexity cardiology center. Despite a high incidence of arrhythmias, no statistical difference was observed in this aspect when comparing both protocols, even when considering the exercise and recovery phases.

When evaluating the morphological patterns of ST segment depression, we observed that the Bruce protocol had a higher chance of detecting morphologies related to a worse prognosis. It is known that downsloping and horizontal morphologies are related to a higher ischemic load and a probability of multi-arterial impairment. ${ }^{32,33}$ Guidelines diverge when associating the upsloping morphology with an ischemic response, but it has been shown that this morphology may be associated with CAD, even if associated with better prognosis and a lower ischemia extent when compared to the downsloping and horizontal morphologies. ${ }^{11,33-35}$

Studies performed for evaluating the diagnostic power of exercise tests present heterogeneous methodologies and most of them used staged protocols, particularly the Bruce protocol. Therefore, sensitivity and specificity values present a wide variation in the literature. ${ }^{7}$ Data for the Bruce protocol obtained in this work are within value intervals from previously published studies. ${ }^{7,36,37}$ Moreover, data referring to the sensitivity, specificity, and accuracy of the exercise test using the ramp protocol were similar to results obtained by Macedo Júnior and Silva $(2015)^{38}$.

Aspects that may explain a higher number of tests suggesting myocardial ischemia at the Bruce protocol include a higher heart rate and double product at peak exercise, secondary to more abrupt increments. It is known that an increase in heart rate generates higher oxygen consumption by the myocardium, while an elevation of the double product is associated with a reduction in myocardial perfusion. ${ }^{12,20}$ In our study, we observed that the ramp protocol presented a lower sensitivity for detecting myocardial ischemia. This finding could be related to lower increments at each stage, which would result in an attenuation of the ischemic response, as demonstrated by other studies. ${ }^{20,39,40}$

For assessing only the test's diagnostic power, without the influence of disease prevalence, we used likelihood ratios. The positive likelihood ratio for the ramp protocol was slightly higher, that is, a positive test had a stronger influence in confirming the probability of myocardial ischemia. On the other hand, the negative likelihood 
ratio was lower in the Bruce protocol, indicating that a negative test represented a lower probability of ischemia. Our likelihood ratio values are compatible with those of Thiers et al., ${ }^{37}$ who evaluated diagnostic thresholds of non-invasive tests for CAD.

Finally, the interpretation of the exercise test should not be limited to the electrocardiographic pattern. Clinical and hemodynamic variables are fundamentally important for result interpretation, providing relevant information to the diagnosis, prognosis, and clinical conduct. Therefore, the choice of the test and best protocol for investigating ischemia should always consider the patient's clinical characteristics and the objective to which the test is being requested. In case the exercise test has the main objective of screening for CAD, protocols with higher sensitivity are recommended. That is, based on the data presented by this study, the Bruce protocol is a better alternative when compared to the ramp protocol.

Among possible limitations of this study, we highlight the smaller sample size when compared with the initial calculation. This information reflects a lower statistical power that was achieved with the evaluated sample. We also note the availability bias, that is, patients with less cardiovascular limitations are more prone to accepting to participate in studies, also indicating a small number of participants with systemic perfusion alterations observed through myocardial scintigraphy.

\section{Conclusion}

The ramp protocol, when compared to the Bruce protocol, had higher specificity and accuracy. However, a higher sensitivity achieved by the Bruce protocol favors its use in exercise testing when screening patients for myocardial ischemia is the main goal.

We had more participants with positive criteria for ischemia at the exercise test using the Bruce protocol and a higher chance of developing horizontal and downsloping ST segment depression, which are associated with a worse prognosis. The main variables found in this study that justified this finding were higher heart rate and double product at peak exercise at the Bruce protocol.

The achieved workload and maximum systolic arterial pressure were similar in both protocols. No significant difference was observed on the incidence of arrhythmias.

\section{Author contributions}

Conception and design of the research: Fagundes, TTS; Mizzaci, CC; Wohnrath, FC; Meneghelo, RS. Acquisition of data: Fagundes, TTS; Mizzaci, CC; Wohnrath, FC; Medina, FRC; Buglia, S. Analysis and interpretation of the data: Fagundes, TTS; Mizzaci, CC; Buglia, S; Meneghelo, RS. Statistical analysis: Fagundes, TTS; Mizzaci, CC; Meneghelo, RS; França, JID. Writing of the manuscript: Fagundes, TTS; Mizzaci, CC; Meneghelo, RS. Critical revision of the manuscript for intellectual content: Fagundes, TTS; Mizzaci, CC; Meneghelo, RS; Buchler, RDD; Mastrocolla, LE.

\section{Potential Conflict of Interest}

No potential conflict of interest relevant to this article was reported.

\section{Sources of Funding}

There were no external funding sources for this study.

\section{Study Association}

This article is part of the thesis of master submitted by Thiago Fagundes, from Instituto Dante Pazzanese de Cardiologia, São Paulo.

\section{Ethics approval and consent to participate}

This study was approved by the Ethics Committee of the Instituto Dante Pazzanese de Cardiologia under the protocol number 2928697. All the procedures in this study were in accordance with the 1975 Helsinki Declaration, updated in 2013. Informed consent was obtained from all participants included in the study. 


\section{References}

1. Meneghelo R, Araújo C, Stein R, Mastrocolla L, Albuquerque P, Serra S. III Diretrizes da Sociedade Brasileira de Cardiologia sobre teste ergométrico. Arq Bras Cardiol. 2010;95(5 Suppl 1):1-26.

2. Kelly JP, Andonian BJ, Patel MJ, Huang Z, Shaw LK, McGarrah RW, et al. Trends in cardiorespiratory fitness: The evolution of exercise treadmill testing at a single Academic Medical Center from 1970 to 2012. Am Heart J. April 2019;210:88-97.

3. Froelicher VF, Myers J. Exercise and the Heart. 5th ed. Philadelphia: Elsevier; 2006.

4. Whipp BJ, Davis JA, Torres F, Wasserman K. A test to determine parameters of aerobic function during exercise. J Appl Physiol. 1981;50(1):217-21.

5. Myers J, Buchanan N, Walsh D, Kraemer M, McAuley P, HamiltonWessler $\mathrm{M}$, et al. Comparison of the ramp versus standard exercise protocols. J Am Coll Cardiol. 1991;17(6):1334-42.

6. Myers J, Bellin D. Ramp Exercise Protocols for Clinical and Cardiopulmonary Exercise Testing. Sport Med. 2000;30(1):23-9.

7. Gibbons RJ, Balady GJ, Timothy Bricker J, Chaitman BR, Fletcher GF, Froelicher VF, et al. ACC/AHA 2002 guideline update for exercise testing: summary article. J Am Coll Cardiol. 2002;40(8):1531-40.

8. Riebe D, Ehrman JK, Liguori G, Magal M. Diretrizes do ACSM para os testes de esforço e sua prescrição. 10a ed. Philadelphia: Guanabara Koogan; 2018.

9. Sealed Envelope Ltd. Create a blocked randomisation list. [Internet]. [Cited in 2020 May 23]. Available from: https://www.sealedenvelope. com/simple-randomiser/v1/lists.

10. Mastrocola LE, Amorim BJ, Vitola JV, Brandão SCS, Grossman GB, Lima $\mathrm{R}$ de SL, et al. Atualização da Diretriz Brasileira de Cardiologia Nuclear - 2020. Arq Bras Cardiol. 2020;325-429.

11. Fletcher GF, Ades PA, Kligfield P, Arena R, Balady GJ, Bittner VA, et al. Exercise standards for testing and training: A scientific statement from the American heart association. Circulation. 2013;128(8):873-934.

12. Zipes D, Libby P, Bonow R, Mann D, Tomaselli G. Braunwald's Heart Disease: A Textbook of Cardiovascular Medicine. 11th ed. Philadelphia: Elsevier Inc.; 2019.

13. Maranhão-Neto GA, Leon ACP, Farinatti PTV. Validade e equivalência da versão em português do Veterans Specific Activity Questionnaire. Arq Bras Cardiol. agosto de 2011;97(2):130-5.

14. Kokkinos P, Kaminsky LA, Arena R, Zhang J, Myers J. New Generalized Equation for Predicting Maximal Oxygen Uptake (from the Fitness Registry and the Importance of Exercise National Database). Am J Cardiol. 2017;120(4):688-92.

15. Luong MW, Ignaszewski M, Taylor M. Stress testing: A contribution from Dr Robert A. Bruce, father of exercise cardiology. BCMJ. 2016;58(2):70-6.

16. Patel MR, Calhoon JH, Dehmer GJ, Grantham JA, Maddox TM, Maron DJ, et al. ACC/AATS/AHA/ASE/ASNC/SCAI/SCCT/STS 2017 Appropriate Use Criteria for Coronary Revascularization in Patients With Stable Ischemic Heart Disease. J Nucl Cardiol. 12 de outubro de 2017;24(5):1759-92.

17. Buchfuhrer MJ, Hansen JE, Robinson TE, Sue DY, Wasserman K, Whipp BJ. Optimizing the exercise protocol for cardiopulmonary assessment. J Appl Physiol Respir Environ Exerc Physiol. 1983;55(5):1558-64.

18. Myers J, Froelicher VF. Optimizing the exercise test for pharmacological investigations. Circulation. 1990;82(5):1839-46.

19. Chalela WA, Meneghetti JC, Moffa PJ. Estresse cardiovascular: princípios e aplicações clínicas. São Paulo: Roca; 2004.

20. Noël M, Jobin J, Poirier P, Dagenais GR, Bogaty P. Different Thresholds of Myocardial Ischemia in Ramp and Standard Bruce Protocol Exercise Tests in Patients With Positive Exercise Stress Tests and Angiographically Demonstrated Coronary Arterial Narrowing. Am J Cardiol. 2007;99(7):921-4.

21. Noël M, Jobin J, Marcoux A, Poirier P, Dagenais G, Bogaty P. Comparison of Myocardial Ischemia on the Ergocycle Versus the Treadmill in Patients With Coronary Heart Disease. Am J Cardiol. 2010;105(5):633-9.
22. Myers J, Bader D, Madhavan R, Froelicher V. Validation of a specific activity questionnaire to estimate exercise tolerance in patients referred for exercise testing. Am Heart J. 2001;142(6):1041-6.

23. Maeder M, Wolber T, Atefy R, Gadza M, Ammann P, Myers J, et al. A nomogram to select the optimal treadmill ramp protocol in subjects with high exercise capacity: Validation and comparison with the Bruce protocol. J Cardiopulm Rehabil. 2006;26(1):16-23.

24. de Oliveira Brito LV, Maranhao Neto GA, Moraes H, Emerick RF e S, Deslandes AC. Relationship between level of independence in activities of daily living and estimated cardiovascular capacity in elderly women. Arch Gerontol Geriatr. 2014;59(2):367-71.

25. Kaminsky LA, Myers J, Arena R. Determining Cardiorespiratory Fitness With Precision: Compendium of Findings From the FRIEND Registry. Prog Cardiovasc Dis. 2019;62(1):76-82.

26. Jang WY, Kang DO, Park Y, Lee J, Kim W, Choi JY, et al. Validation of FRIEND and ACSM Equations for Cardiorespiratory Fitness: Comparison to Direct Measurement in CAD Patients. J Clin Med. 2020;9(6):1889.

27. Jouven X, Zureik M, Desnos M, Courbon D, Ducimetière P. Long-Term Outcome in Asymptomatic Men with Exercise-Induced Premature Ventricular Depolarizations. N Engl J Med. 2000;343(12):826-33.

28. Califf RM, McKinnis RA, McNeer JF, Harrell FE, Lee KL, Pryor DB, et al. Prognostic value of ventricular arrhythmias associated with treadmill exercise testing in patients studied with cardiac catheterization for suspected ischemic heart disease. J Am Coll Cardiol. 1983;2(6):1060-7.

29. Evans $\mathrm{CH}$, Harris G, Menold V, Ellestad MH. A basic approach to the interpretation of the exercise test. Prim Care Clin Off Pract. 2001;28(1):73-98.

30. Dewey F, Kapoor J, Williams R, Lipinski M, Ashley E, Hadley D, et al. Ventricular Arrhythmias During Clinical Treadmill Testing and Prognosis. Arch Intern Med. 2008;168(2):225.

31. Lee V, Perera D, Lambiase P. Prognostic significance of exercise-induced premature ventricular complexes: a systematic review and meta-analysis of observational studies. Heart Asia. 2017;9(1):14-24.

32. Polizos G, Ellestad MH. The Value of Upsloping ST Depression in Diagnosing Myocardial Ischemia. Ann Noninvasive Electrocardiol. 2006;11(3):237-40.

33. Stuart RJ, Ellestad MH. Upsloping S-T segments in exercise stress testing Am J Cardiol. 1976;37(1):19-22.

34. Kurita A, Chaitman BR, Bourassa MG. Significance of exercise-induced junctional S-T depression in evaluation of coronary artery disease. Am J Cardiol. 1977;40(4):492-7.

35. Desai MY, Crugnale S, Mondeau J, Helin K, Mannting F. Slow upsloping ST-segment depression during exercise: Does it really signify a positive stress test? Am Heart J. 2002;143(3):482-7.

36. Knuuti J, Ballo H, Juarez-Orozco LE, Saraste A, Kolh P, Rutjes AWS, et al The performance of non-invasive tests to rule-in and rule-out significant coronary artery stenosis in patients with stable angina: a meta-analysis focused on post-test disease probability. Eur Heart J. 2018;39(35):3322-30.

37. Thiers CA, Barbosa JL, Tura BR, Arruda EF, Pereira B de B. Performance of Diagnostic Tests for Intermediate Probabilities of Coronary Heart Disease: A Decision Making Analysis. Int J Cardiovasc Sci. 2017.

38. Macedo Júnior ARA, Barbosa e Silva O. Acurácia do Protocolo em Rampa na Detecção de Isquemia Miocárdica. Rev do DERC. 2015;21(4):122-6.

39. Panza JA, Quyyumi AA, Diodati JG, Callahan TS, Epstein SE. Prediction of the frequency and duration of ambulatory myocardial ischemia in patients with stable coronary artery disease by determination of the ischemic threshold from exercise testing: Importance of the exercise protocol. J Am Coll Cardiol. 1991;17(3):657-63.

40. Tamesis B, Stelken A, Byers S, Shaw L, Younis L, Miller DD, et al. Comparison of the Asymptomatic Cardiac Ischemia Pilot and modified Asymptomatic Cardiac Ischemia Pilot versus Bruce and Cornell exercise protocols. Am J Cardiol. 1993;72(9):715-20. 